\title{
THE TWENTY FOURTH PROFESSOR CHIN FUNG KEE MEMORIAL LECTURE
}

\author{
Presented at the Auditorium Tan Sri Prof. Chin Fung Kee, \\ Wisma IEM, Jalan Selangor, 46200 Petaling Jaya, Selangor, Malaysia \\ on 15th November 2014
}

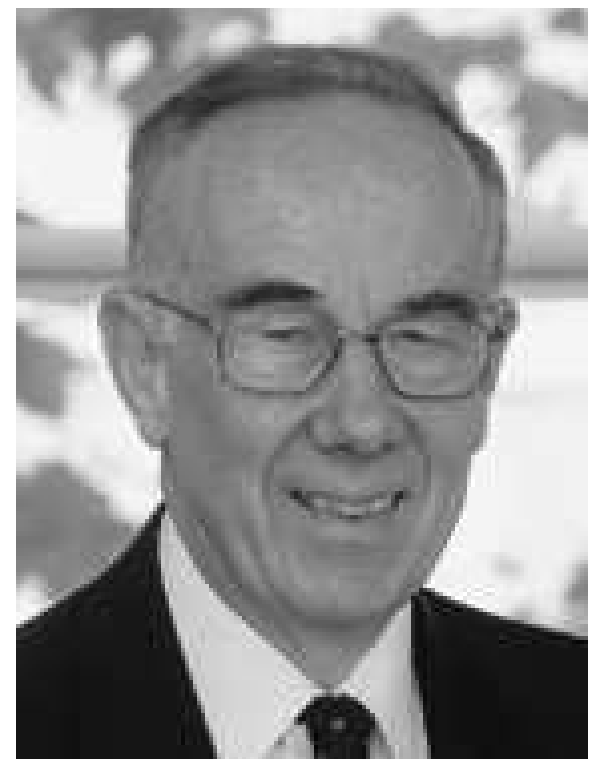

Dr Brian Simpson

OBE, FREng, MA, PhD, FICE, EurIng

Arup Fellow, Arup, London, UK

Honorary Professor, University of Nottingham, UK

Dr Brian Simpson is an Arup Fellow, a principal of Arup Geotechnics and an Honorary Professor at the University of Nottingham, UK. He has worked on a wide range of geotechnical and ground-structure interaction problems, including foundations, excavations, retaining structures and tunnels. His $\mathrm{PhD}$ studies at the University of Cambridge were in the early development of finite element modelling of geotechnical materials and design problems, a topic in which he has remained active throughout his career. He has led the geotechnical design and analysis of a number of large basement projects in London, starting with the British Library for which innovating approaches to modelling and safety formats were developed. More recently he has advised on the design and analysis of major infrastructure developments in and around London, including the Jubilee Line, Channel Tunnel Rail Link, redevelopment of Kings Cross and CrossRail. He has been an expert witness on major disputes and investigations of collapse in the UK, Singapore and New Zealand.
Dr Simpson presented the BGA Rankine Lecture in 1992 and a State-of-the-Art report on Geotechnical Analysis and Design at the 2009 international conference of ISSMGE.

Since the early 1980's, Dr Simpson has been involved in the development of Eurocode 7 (Geotechnical Design), having been a member of its drafting panels and vice-chairman of the CEN (Comité Européen de Normalisation) committee on Eurocode 7 (SC7). He has authored two commentaries on Eurocode 7 and several papers on various related issues. He is the current chair of ISSMGE Technical Committee TC205 on Safety and Serviceability in Geotechnical Engineering and of the BSI committee on geotechnical codes, B/526. He is often the UK delegate to SC7 and is a member of several of the "Evolution Groups" set up to propose further developments of Eurocode 7. 


\title{
SEEKING THE CODE OF THE GROUND
}

\author{
(Date received: 12/05/2015/Date accepted: 14/03/2016) \\ ${ }^{1}$ Brian Simpson \\ ${ }^{1}$ OBE, FREng, MA, PhD, FICE, EurIng Arup Fellow, Arup, London, UK \\ Honorary Professor, University of Nottingham, UK. \\ Email: Brian.Simpson@Arup.com
}

\begin{abstract}
This paper explores three topics that constantly challenge geotechnical engineers: deformation, water and safety. More specifically, these topics involve understanding and predicting deformation, designing safely when water pressure is dominant, and, more generally, trying to manage the many uncertainties we face in a rational manner that can be agreed and communicated to others. Evolving understanding of the secrets coded in the ground have led to developments in computer codes for ground deformation and codes of practice for geotechnical design.

Using the author's own career as a background, the paper considers the development of ideas related to these topics over the past forty years. This is not a monotonic process: ideas and understand from one project may lie dormant for some years and then be developed when a fresh need arises at a later stage. Equally important are the colleagues and mentors with whom problems can be addressed and ideas discussed; some outstanding individuals will be acknowledged.
\end{abstract}

\subsection{INTRODUCTION}

Engineering in the ground is fascinating, very challenging, and it involves a huge array of skills and disciplines. In the author's career, it seems that three topics, in particular, have repeatedly come to the forefront: understanding and predicting deformation, designing safely when water pressure is dominant, and, more generally, trying to manage the many uncertainties we face in a rational manner that can be agreed and communicated to others.

Engineers are concerned with the "built environment", but the environment in which geotechnical engineers work is usually not built by humans - it is the product of nature, or sometimes it is the remnant left from historic human activity. The ground is intriguing, frustrating and unruly. It holds many secrets and does not submit readily to our rules.

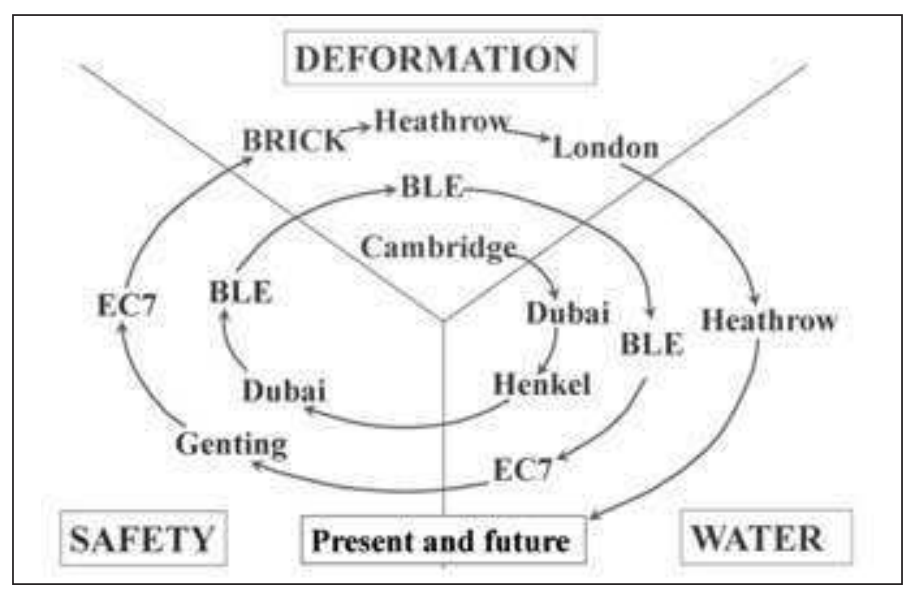

Figure 1: Sequence of experience and ideas
So perhaps the ground's secrets could be regarded as its own secret code. It is often said that geotechnical engineering is a mysterious art, implying that participants communicate with each other in a suspicious code which cannot be penetrated by the rational mind. But if we are to work with the ground in a rational and systematic way, we need to have a different type of code to guide our behaviour - a code of practice. And in studying the ground and trying to predict its behaviour we probably need computer codes. All of these codes will feature in this paper.

A historical review of the development of ideas related to these topics, based on the author's own career, is illustrated in Figure 1. Experience is gained gradually, and ideas and understand from one project may lie dormant for some years and then be developed when a fresh need a rises at a later stage.

\subsection{CAMBRIDGE}

The 1960's was an exciting period of early development for geotechnical engineering, and in particular for the development

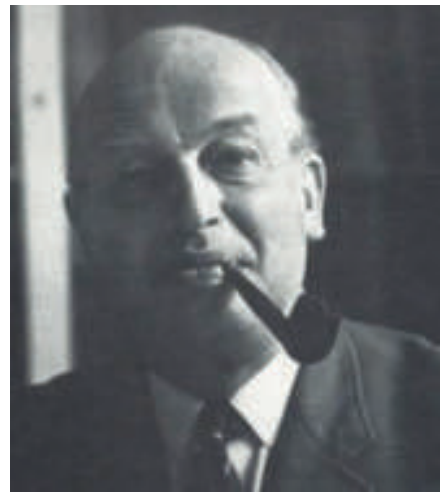

Figure 2: Professor Ken Roscoe

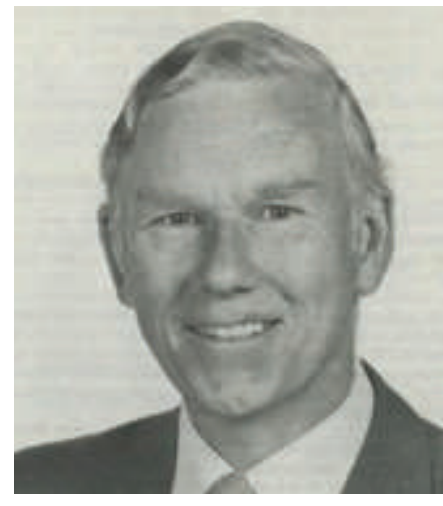

Figure 3: Professor Peter Wroth 
of stress-strain models of soil behaviour, incorporating both deformation and failure. The author was privileged to carry out $\mathrm{PhD}$ research at Cambridge University in the UK, where the team was led by Professor Ken Roscoe, Figure 2. The importance of the yield points and strength of soils, generally expressed in terms of stress states, were well recognised, and the Cambridge team at this time had developed the plasticity models of soil behaviour Granta-gravel and Cam-clay (Schofield and Wroth 1968). But they also particularly recognised the importance of understanding the deformation characteristics of soil, emphasising strain and displacements as well and stress and equilibrium. For his Rankine Lecture, Roscoe (1970) chose the title "The influence of strains in soil mechanics", whilst his student, now Professor, John Burland headed his thesis with the prescient words "Stress is a philosophical concept. Deformation is the physical reality."

Civil engineers are rightly taught the importance of ensuring equilibrium of stresses and forces in engineering analysis, and calculations of limiting equilibrium are the basis of much design. However, displacement and strain are often of equally critical importance yet sometimes overlooked; perhaps this is partly because they are even more difficult to predict.

The 1960's also saw the first stages of development of finite element modelling. The author worked under the supervision of Professor Peter Wroth (Figure 3) to develop one of the first finite element programs to incorporate Cam-clay models and other developments of them for both clays and sands (Simpson 1973, Simpson and Wroth 1972, Wroth and Simpson 1972). Parallel work was being carried out in Swansea by a student of Professor Zienkiewicz, David Naylor (Zienkiewicz and Naylor 1971).

Whilst finite element modelling was ideally suited to linear elasticity, it was very evident from the start that any attempt to model the deformation behaviour of soils had to accommodate highly non-linear behaviour.

In the Grata gravel and Cam-clay models, it was assumed that the volumetric deformation of soils, within a yield surface, was elastic (ie recoverable) and essentially linear, though with stiffness proportional to mean effective stress, and that there was no elastic shear deformation. This assumption of rigidity in shear was inconvenient for finite element modelling, implying an elastic Poisson's ratio $v=-1$. The author and Naylor both thought this was unlikely, as apparently did later workers, so substituted more "conventional" behaviour, allowing some shear elasticity, with values of $v$ in the range 0.2 to 0.4 . This

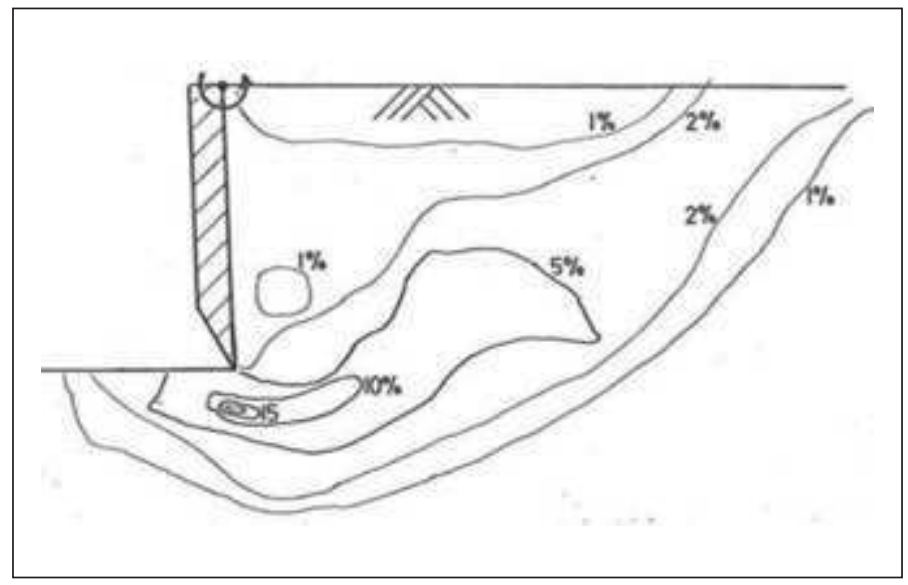

Figure 4: Shear strains computed for a wall rotating about its top assumption may have been unfortunate, as will be discussed in 7.1, below. Nevertheless, these early models made it possible to reproduce some aspects of the behaviour of soils observed in model tests on simple materials such as kaolin clay and Leighton Buzzard sand. An early example of shear strains computed for a rotating wall is shown in Figure 4.

\subsection{DUBAI DRY DOCK}

\subsection{Water and safety - the temporary cofferdam}

During the early 1970s the Suez Canal was closed and it was anticipated that very large (1 million tonne) tankers would be needed to take oil from the Middle East to Europe, travelling around the tip of South Africa. In preparation for this, very large dry docks were built in the Arabian Gulf, one of which was in Dubai. When it was constructed, the Dubai Dry Dock was the largest in the world, actually a complex of three parallel docks (Daniels and Sharp 1979, Cochrane et al 1979). Figure 5 shows the docks under construction.

The dry dock was constructed in an excavation below sea level, protected partly by an earth bund and partly by cellular cofferdams. The bund was placed by dredging hydraulic fill, with an intended cross section as shown in Figure 6a. A sheet pile core was intended to reduce the hydraulic gradients in the downstream part of the bund, and the downstream face would be protected by placing a toe drain of more permeable material before other fill was placed on top. In the event, it appears that after the downstream toe was placed fines built up on top of it, forming a partial seal, as shown in Figure 6b, with the result that water emerged from the slope and started to erode it rapidly.

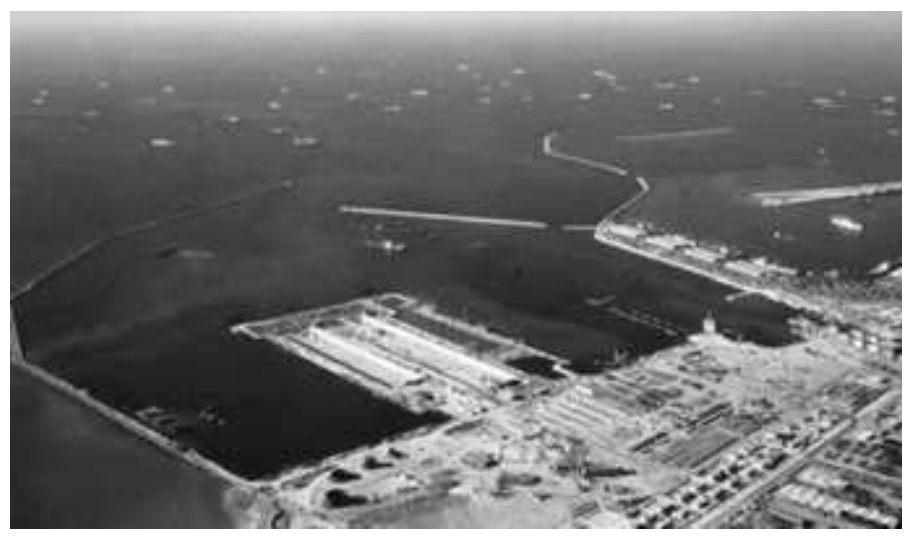

Figure 5: Dubai Dry Dock under construction

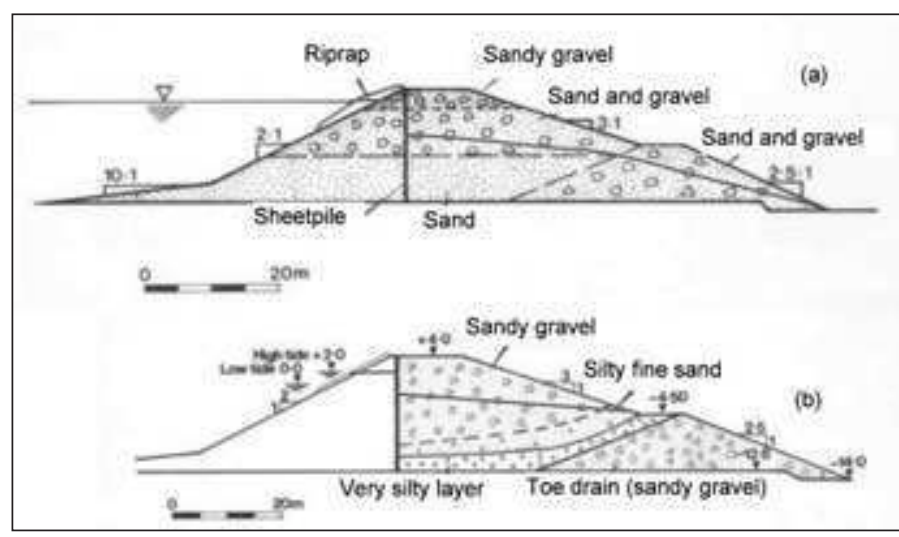

Figure 6: Dubai Dry Dock - cross sections of earth bund: (a) as intended; (b) as built. 
This was an alarming situation, as can be seen in Figure 7, but fortunately rapid action was taken to place more coarse material and a disaster was averted. This incident powerfully illustrates the fact that in design of any situation involving water seepage it is essential to know the distribution of permeability in the ground or, since it can never be known, to make sufficiently cautious assumptions.

Towards the end of the life of the cofferdam a small disturbance to abandoned sheet piles unexpectedly caused further alarming erosion at the downstream toe. Again, remedial action was needed, and the author proposed that it would be wise to obtain a calculated factor of safety against slope failure of 1.25. The project manager responded, "Yes, I will buy 25\% safety!" The author reflected that neither he nor the project manager really understood what they meant by these numbers.

\subsection{Water - the dock gates}

Figure 8 shows a dock gate closed after the temporary cofferdam had been flooded. The dock gates were designed to be supported by props bearing on thrust blocks. The primary load on the gates was from the water pressure of the sea, and it was proposed that a factor of safety was needed in the design of this system. Several alternative proposals were suggested for the definition of a suitable factor of safety applied to water pressures. One of the proposals suggested, unreasonably, that the gate would be unstable when the dock was full of water and water pressures were equal on either side of the wall.

Arup were responsible to Costain Taylor Woodrow, the joint venture contractors, for geotechnical design of the dock, and Arup's work was led by a very eminent geotechnical engineer, Dr David Henkel, Figure 9. To illustrate the issues of factors of safety in relation to water pressures, Henkel asked the question, "What is the factor of safety against a brick jumping off the base of a swimming pool? And what does it mean?" Years later, this question has been illustrated, in terms of an anchor block, as noted in 5.1 below.

The practical significance of these issues was dramatically illustrated in 2002 when part of a dock gate collapsed and many lives were lost of workers inside the dock. This was not a geotechnical failure, but it clearly showed the importance of having sufficient safety in situations where water pressure is a dominant load.

\subsection{Tank settlement - soil has memory}

Many of the land-based facilities of the dry dock were built on ground reclaimed by pumping hydraulic fill. Settlement markers were placed in the fill to gauge the compressibility of the fill,

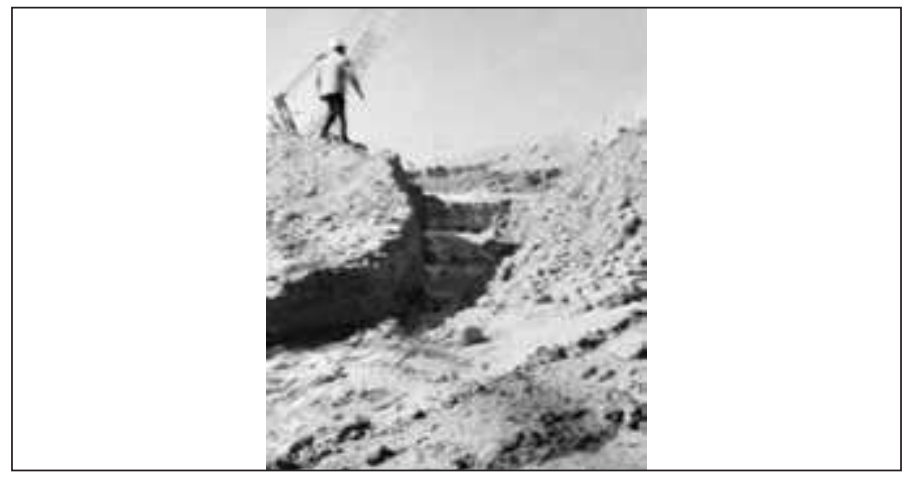

Figure 7: Dubai Dry Dock - rapid erosion of the downstream face of the bund. which penetration tests (SPT and CPT) showed to be very loose. Several years later, fuel tanks were built on the fill and tested by filling with water, and predicted settlements, based on the compressibilities measured during filling, turned out to be around ten times bigger than measured. On investigation, it was found that the results from new penetration tests were unchanged from the earlier values, but it was also noted that the area had, in the meantime, been surcharged by use as storage area for fill. It appeared that although the density of the dredged fill had not been changed significantly by this loading, its stiffness in reloading was very much greater than in initial loading. In terms of stress-strain behaviour, soil clearly has memory.

\subsection{BRITISH LIBRARY}

The British Library is the national library of the United Kingdom. The library is a major research library, holding around 170 million items from many countries, in many languages. Design and construction of a new library in London spanned two decades from the 1970 s to the 1990 s, the major excavation being carried out in the mid 80s. The structure has up to seven storeys above ground, with the major book storage in basements up to $25 \mathrm{~m}$ deep. Figure 10 is a cross section though the library, showing the $25 \mathrm{~m}$ deep basement immediately adjacent to the Metropolitan and Circle Line of London Underground, with shallower basements spanning over the deeper Victoria and Northern Lines. The design and construction of the library was published by Ryalls and Stevens (1990), and the results of extensive monitoring were published recently by Simpson and Vardanega (2014), who also provide other references. Geotechnical design was led by David Henkel and the author.

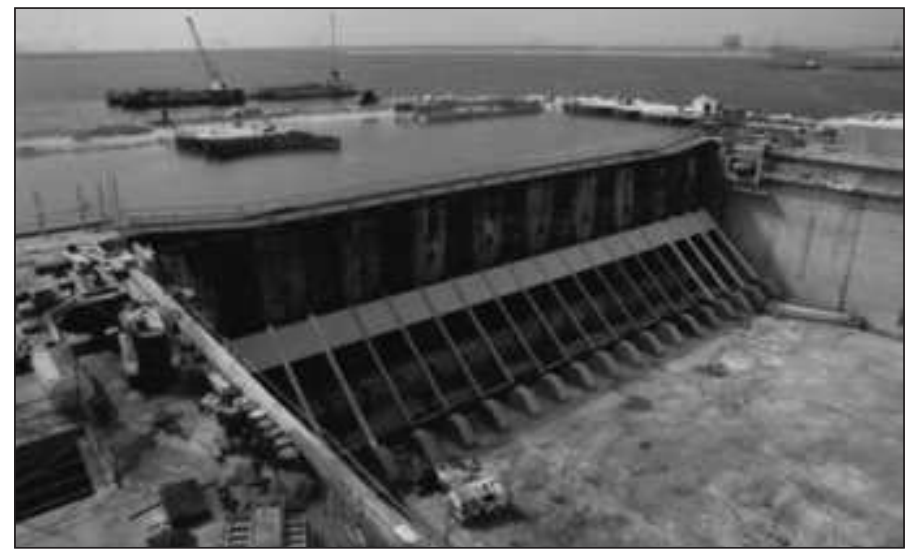

Figure 8: Dubai Dry Dock - dock gates

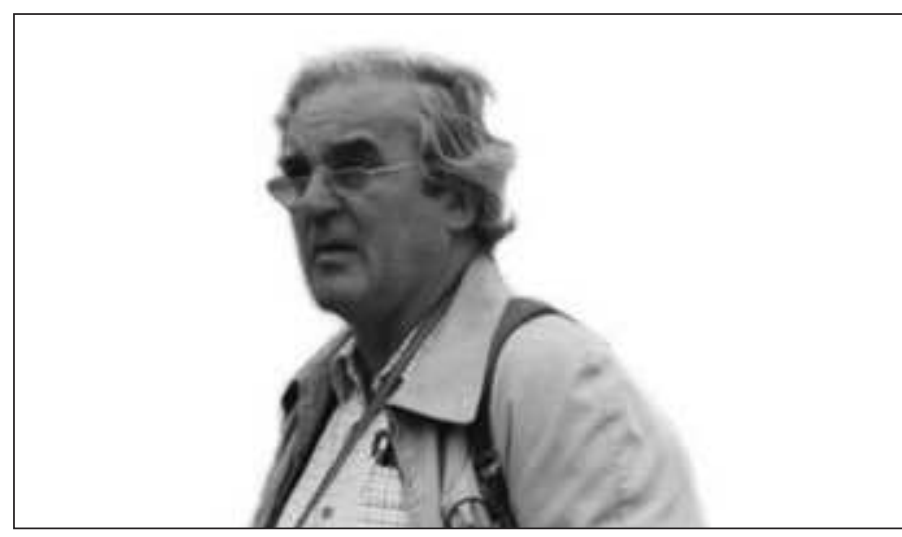

Figure 9: Dr David Henkel 


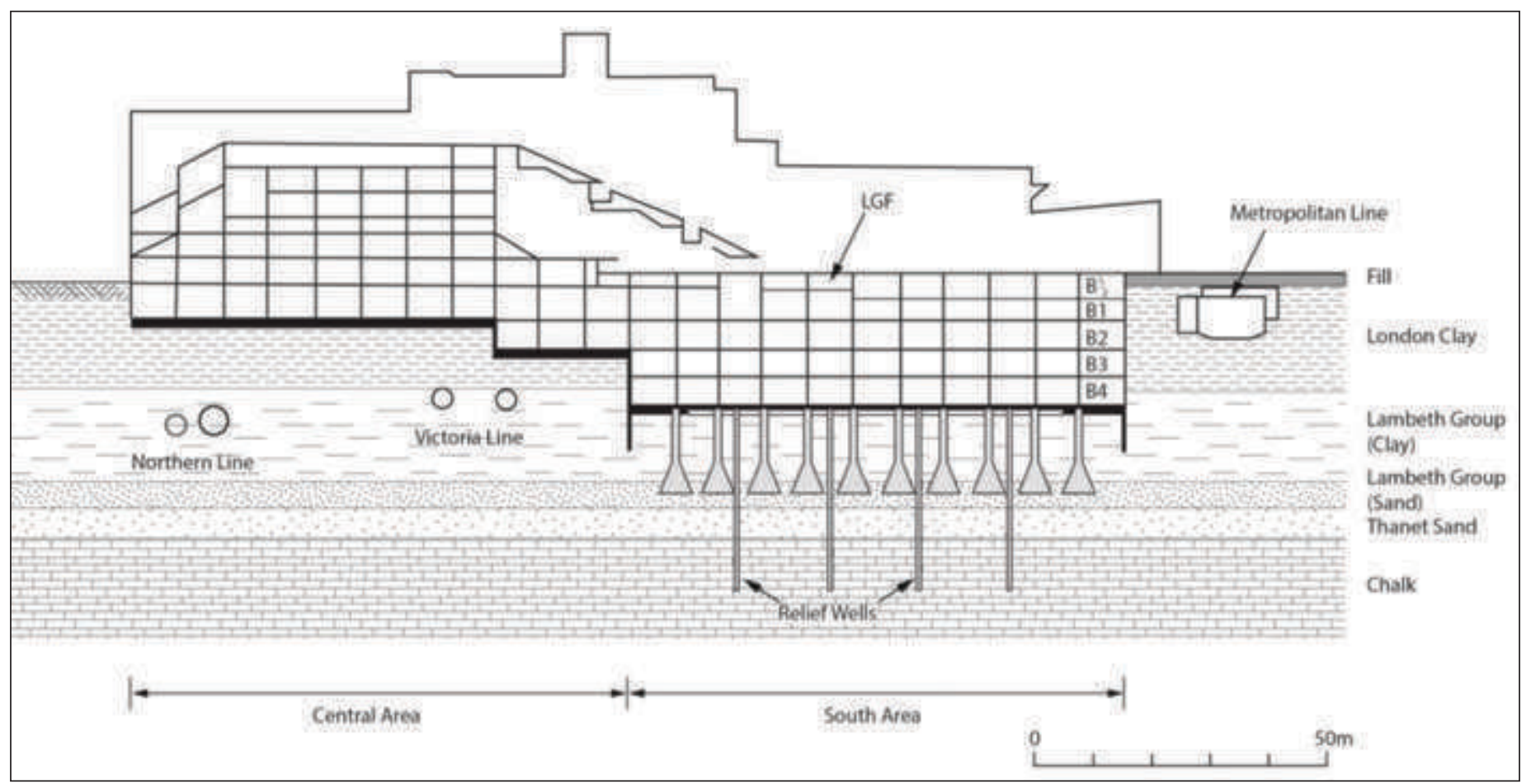

Figure 10: British Library - north-south cross section

\subsection{Deformation of retaining walls and surroundings}

The designers were conscious that this was, at the time, the largest and one of the deepest basements constructed in London, so it was felt that simple extrapolation of previous experience might be unwise. Other workers, notably Burland and Hancock (1977) had shown that assumptions of linear elasticity, used in finite element analysis, gave misleading predictions of ground deformations around deep basements in London. It was therefore concluded that a non-linear model of the behaviour of the London Clay was needed. It was assumed that stiffness at small strains could be very high, with the lower stiffnesses typically

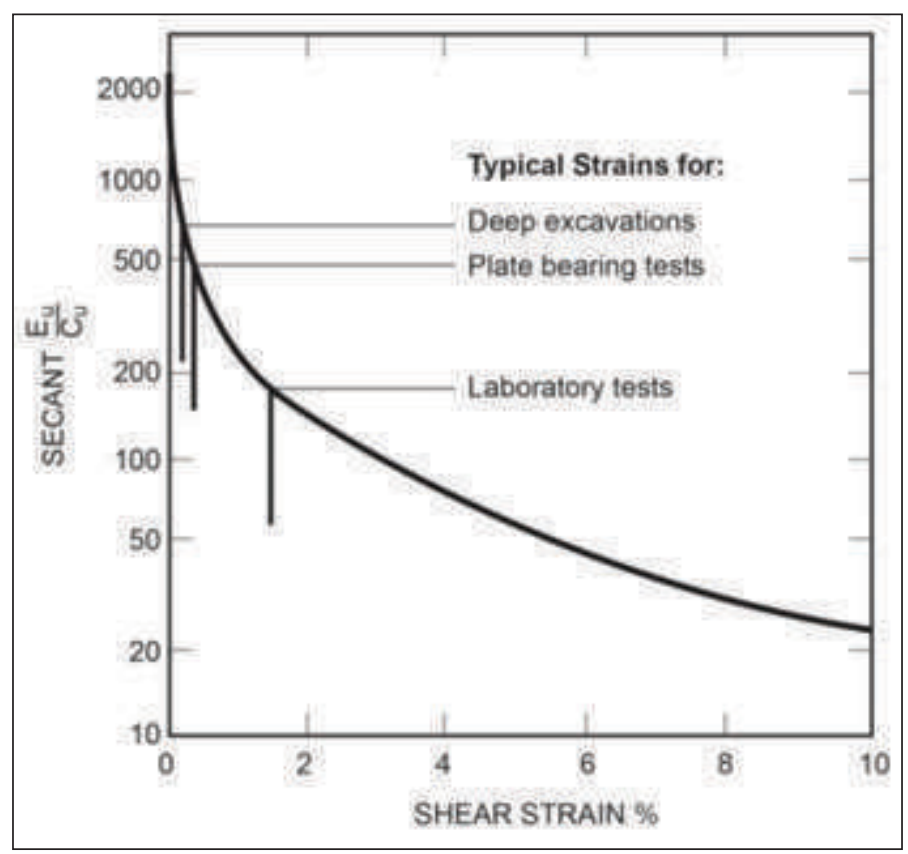

Figure 11: Decay of stiffness with strain. After Simpson et al., (1981a) measured in laboratory tests being appropriate to a larger strain range. Apart from physical reasoning, this concept had the merit that computed displacements would increase disproportionately for larger excavations, which was considered to be sensible conservatism in design.

The thinking behind this and the model itself were published by Simpson et al (1979), showing that a good correlation was achieved with measured ground movements published by Burland and Hancock (1977) for the underground car park at the houses of parliament. Simpson et al., (1981a) showed how this model would predict the gradual decay in secant stiffness as strains increased; Figure 11 shows how this relates to the different stiffnesses apparent in field situations and laboratory tests. The model used, in a simple way, the assumption of a "kinematic yield surface", such that stiffness was high for strains up to a certain magnitude, then dropped immediately to a lower value. This differed in one significant respect from most other plasticity models: the yield surface was expressed in strain space rather than in stress space.

In the event it was found that the model adopted predicted too much displacement, as noted by Simpson (1992). However, the concepts that had been developed would be valuable later.

\subsection{Safety in structural design}

The structure was being designed in the late 1970s when limit state thinking was in its infancy and a sensible approach to strength design (ultimate limit state) for the retaining walls and propping floors was needed. For a basement in stiff clay, it was realised that the stiffness of the ground as well as its strength was important in calculating structural forces and bending moments, as was the in situ ground stress represented by $\mathrm{K}_{0}$. It was also clear that if the worst values were taken of all the available parameters simultaneously the design would be based on an incredibly severe situation and would be extremely conservative. Simpson et al., (1981b) addressed these issues and proposed the 


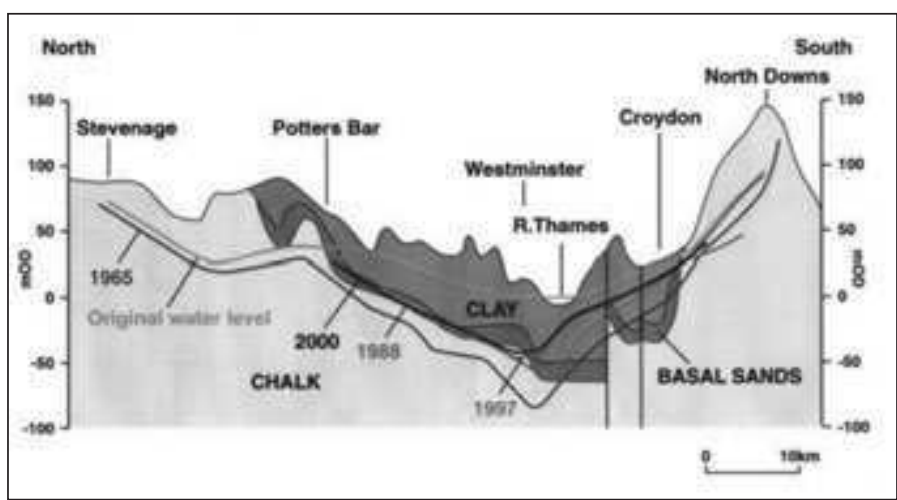

Figure 12: Geological section through London

" $\lambda$-method" in which one parameter was to be taken to an extreme value while others were held at cautious, but not extreme values. This approach was based on probability theory and required a parametric study to find which parameter was the most critical to each aspect of design. An important feature of the method was that the pivot values of parameters, from which other more or less severe values were derived, were not mean, most likely, values but "worst credible"; it was considered important that designers think specifically about the worst that might occur, while mean, or "most probable", values were considered to be of secondary importance.

\subsection{Water}

Figure 12 shows a geological section through London, from about $60 \mathrm{~km}$ north of the centre to about $30 \mathrm{~km}$ south. The centre of London is underlain by the London Clay and other clays, the Basal Sands and the Chalk, which outcrops in hills to the north and south. Originally, before the nineteenth century, the piezometric water level in the aquifer, consisting of the Chalk and Basal Sands, was artesian for low-lying areas in central London. However, as industrialisation progressed in the nineteenth and early twentieth centuries the aquifer was over exploited and the water level fell.

Much industry was destroyed during the Second World War, and rebuilt residential and commercial buildings were supplied with mains water rather than using wells. Consequently water levels in the aquifer started to rise. This was known to the water industry but not to the construction industry until it was noted during discussions about the design of British Library. A similar pattern has since emerged in many other developed cities.

It had been assumed that the water level in the aquifer would always be well below the level of the deepest basement at British Library. However, it now became apparent that this assumption was not reliable in the very long intended design life of the structure. This could lead to a reduction in the bearing capacity of the piled foundations, which extended only $12 \mathrm{~m}$ below the basement, with no surcharge on the clay surface below the suspended basement slab; in the worst case, water pressures in the aquifer could be sufficient to uplift this $12 \mathrm{~m}$ thickness of clay.

Figure 13 shows how the design to the basement was changed as a result of this discovery. The areas of the underreams of the piles were doubled and 32 wells were sunk into the chalk aquifer, for a basement area of around $12,000 \mathrm{~m} 2$. The intention of the wells was that if the water level rises sufficiently they will overflow at basement level, into pumped sumps, controlling the water level in the aquifer beneath the basement and, probably,

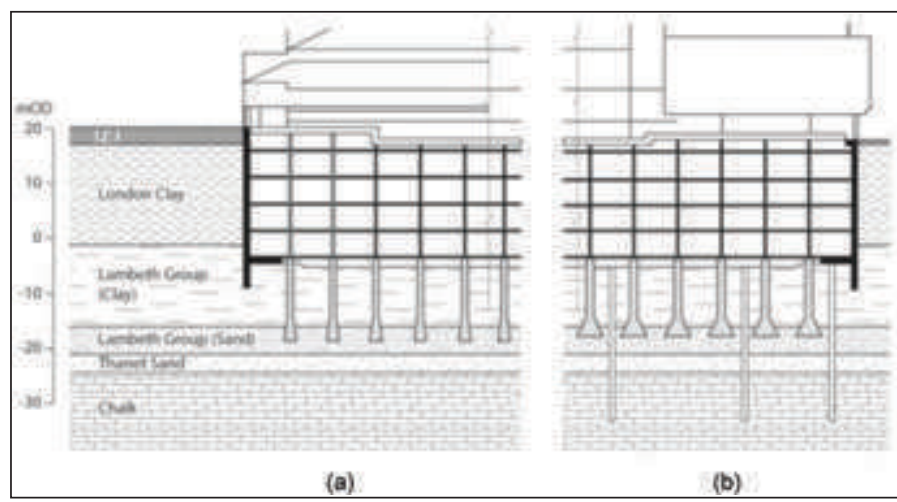

Figure 13: Changes made to British Library design to accommodate rising groundwater levels: (a) initial design; (b) final design.

for a considerable distance around it. Even with this control, the effective overburden pressure at the level of the underreams could be halved, hence the need to double the base areas.

This experience illustrates the importance of knowing, and preferably controlling, water levels in the ground. Application of factors of safety to any water pressures in the aquifer was not considered and would not have been helpful. The findings on this project led to a study for the whole of central London published by CIRIA (Simpson et al., 1989) and by Simpson et al., 1987. The aquifer is now monitored and data are published annually, most recently by Environment Agency (2014). The water level is still almost $20 \mathrm{~m}$ below the level of the underreams.

\subsection{EUROCODE 7}

The Eurocodes are a series of standards for the design of buildings and civil engineering structures that has now been implemented across Europe. Eurocode 7 (EC7) is the standard for geotechnical design (BS EN 1997-1:2004). The author has been involved in the development of EC7 since its instigation in 1981 .

\subsection{Water}

Prescription of safety for design situations dominated by water pressures has often been discussed in the development of EC7 and is still contentious. For design against exceedance of ultimate limit states (serious failures), EC7 requires that "design values [of water pressures] shall represent the most unfavourable values that could occur during the design lifetime of the structure" \{2.4.6.1(6)\}. It is important here to note that the term "design value" means a value with its safety already incorporated, either by means of applying partial factors (commonly used for loads and strengths) or by other means. EC7 allows design values to be derived by applying factors to "characteristic" water pressures, but the UK National Annex warns against this, recommending either "direct assessment" of design values or the code's alternative approach of adding a margin of safety (eg in metres) to characteristic water levels. The code confuses the issue somewhat by specifying some partial factor values for use with water pressures, without being clear about how these should be applied. Some problems this gives have been discussed by Orr (2005) and Simpson (2012).

The managing committee for EC7 (CEN/TC250/SC7, or "SC7") asked three people from different backgrounds to study these issues and prepare a joint paper - Simpson, Vogt and van Seters (2011). They considered a range of simple problems, shown in Figure 14, designed to highlight the various issues, 
together with some more complex examples. They noted that factors of safety on water pressures could often be misleading or unhelpful, and that it is essential to assess the actual worst water pressures, or water level, that the design must be able to accommodate. For example, for the small retaining wall depicted in Figure 14d, the designer has to decide whether to rely on the drain, $1 \mathrm{~m}$ below the top of the wall, or not. If it is assumed that the drain will control the water level, but in the event it does not, the bending moment in the wall will be increased by a factor of about 2.5, way beyond the allowance introduced by partial load factors. The designer cannot offset this critical decision by relying on factors of safety.

Simpson, Vogt and van Seters emphasised the importance for water pressures of the "single source principle". This states that if different forces are derived from a single source (so, in statistical terms they are correlated, not independent), then the same partial factor must be applied to all of them, even if some appear to be favourable (stabilising) and others unfavourable (destabilising). A very simple example of this is shown by the anchor block in Figure 14a. The water force above the block, helping to hold it down (stabilising) and that below the block lifting it up (destabilising) both come from the same body of water and are not independent. Factoring them differently leads to preposterous results. Although this example seems naively simple, it illustrates a principle that can be generally applied, but is sometimes not so obvious. These authors concluded that factors might be applied to differential water pressures, but generally not to individual water pressures.

The authors considered various ways of characterising the safety against uplift of the piled basement shown in Figure 14b. Specifying a margin to be added to the water level seemed to be more sensible than the available options for applying factors to water pressures.

Although these authors, from different backgrounds, were able to draw some provisional conclusions, they did not agree in all respects and they recorded the items that were not resolved in the paper. Following this, an "Evolution Group" has been formed by SC7 to study the problems further. This has not yet produced its final report, but it seems likely that it will recommend that no factors should be applied to water pressures or the forces derived from water pressures, except that structural bending moments and internal forces should be factored when derived from water pressure loads, giving consistency with structural codes. For ultimate limit states, the design water pressure will be designed as one having a defined, small, probability of occurrence within the design life of the structure, the default probability being $1 \%$. For serviceability limit states, the "characteristic" water pressure is defined to have a return period equal to the design life of the structure, giving a probability of occurrence typically of about $63 \%$. It should be noted that for temporary works the design life might be quite short, such as a few months or one to two years.

\subsection{Safety - Design Approach 1}

Eurocode 7 offers several different "Design approaches" indicating how sets of partial factors may be combined for ultimate limit state design. In this paper only Design Approach 1 (DA1), adopted by the UK, some other European countries, Malaysia and Singapore will be considered. The values of partial factors normally used for design of spread foundations, slope stability and retaining structures are shown in Table 1. In DA1, calculations are required for two "combinations" of

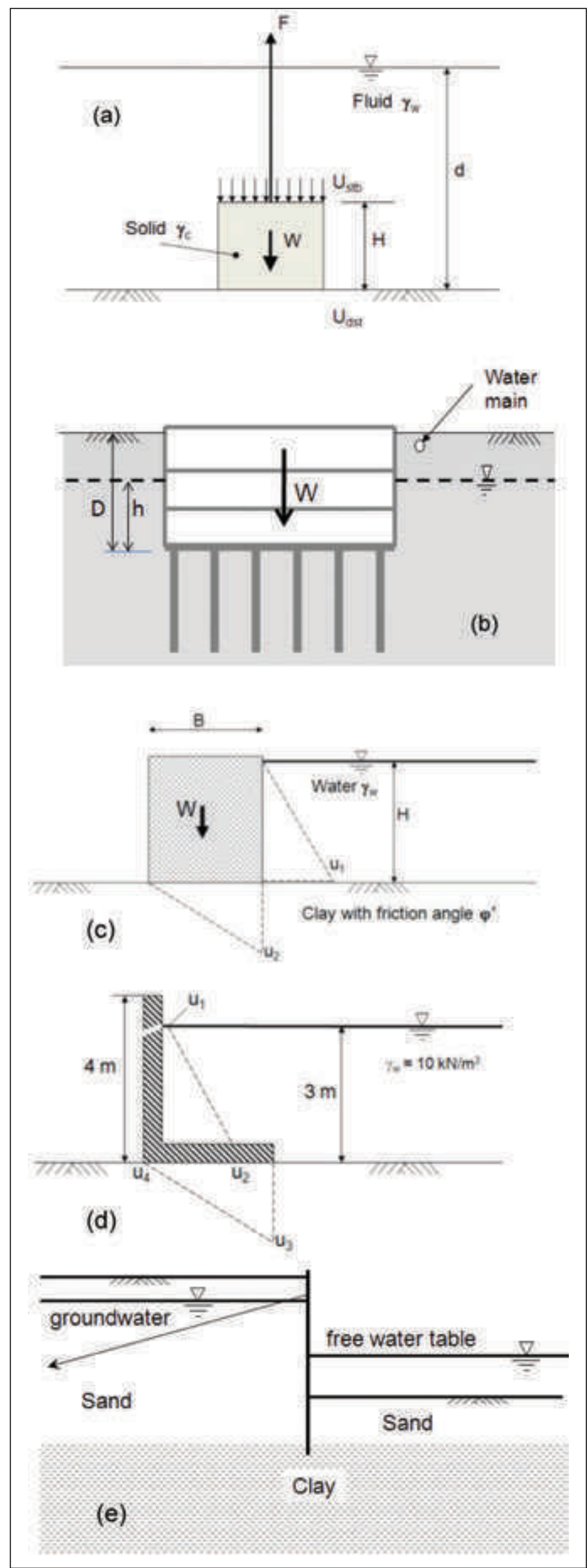

Figure 14: "Simple" problems of water pressures considered by Simpson et al., (2011) 
Table 1: Values of partial factors normally used for DA1, for design of spread foundations, slope stability and retaining structures

\begin{tabular}{|c|c|c|c|c|}
\hline & & & \multicolumn{2}{|l|}{ DA1 } \\
\hline & & & Comb 1 & Comb 2 \\
\hline \multirow[t]{3}{*}{ Actions } & Permanent & unfav & 1,35 & \\
\hline & & fav & & \\
\hline & Variable & unfav & 1,5 & 1,3 \\
\hline \multirow[t]{4}{*}{ Soil } & \multicolumn{3}{|l|}{$\tan \varphi^{\prime}$} & 1,25 \\
\hline & \multicolumn{3}{|c|}{ Effective cohesion } & 1.25 \\
\hline & \multicolumn{3}{|c|}{ Undrained strength } & 1,4 \\
\hline & \multicolumn{3}{|c|}{ Unconfined strength } & 1,4 \\
\hline
\end{tabular}

factors, DA1-1 and DA1-2: in DA1-1, the values of actions (or structural effects of actions) are factored, but ground strengths are unfactored; in DA1-2, actions are almost unfactored, but ground strengths are factored. A different approach is taken to Combination 2 for piles and ground anchors, with factors applied to the "resistances" (capacities) of those elements, rather than to ground strength.

Finally, one further major advantage of the application of factors to material strengths in DA1, rather than to resistances such as passive earth pressure, is that it can be used readily to provide complete ULS analyses using finite element programs. This will be discussed further below. This is much more difficult in approaches that apply factors to resistances such as passive earth pressures, for which supplementary calculations, different for each element to be designed, are required.

The basic rule is that the design must accommodate both sets of factors in all respects, both structural and geotechnical. (It is not the case, as sometimes supposed, that DA1-1 is for structural design and DA1-2 for geotechnical design, though the governing criteria for design sometimes follow this pattern.) The other Design Approaches require only one calculation, so the advantages of DA 1 require explanation. This was considered in detail by Simpson (2007), and a few key points will be noted here.

\subsection{Genting Highlands}

Figure 15 shows a residential block situated at the top of a slope. This project is located in Genting Highlands and the author worked on it with Arup in Malaysia some years ago. Calculations showed that with unfactored soil strengths the unsupported slopes would be stable, but this was marginal, with low factors of safety, so it was considered necessary to construct the anchored wall of caissons shown in the figure. The design approach initially used for the wall was to find the forces from the ground using unfactored ground strength, then to apply factors to the structural bending moments and tie forces. This gave a logical problem: for unfactored ground strength, the slope was stable and the wall was not needed, so how could it be designed? In effect, the slope was being designed for DA1-2 and the wall for DA1-1. The real requirement here is that the ground and structure must be designed together for the same conditions, represented by sets of factors. DA1 provides for this. By contrast, DA2, which was intended to have only one calculation, requires a separate calculation, similar to DA1-2, for slope stability but does not follow this through to the structural design.

\subsection{DA1 - theoretical background}

So DA1 requires that the design is checked against two "combinations" of factors, unless it is obvious which of these is critical. This has the obvious disadvantage that it requires slightly more work on the part of the designer, though in practice three factors minimise this problem: (a) it is frequently the case that the critical combination is obvious by inspection; (b) Combination 1 can often be derived from a serviceability limit state calculation, which is required by all the design approaches; (c) most computations are carried out by computer and there is very little difficulty in running a second case, if it is needed.

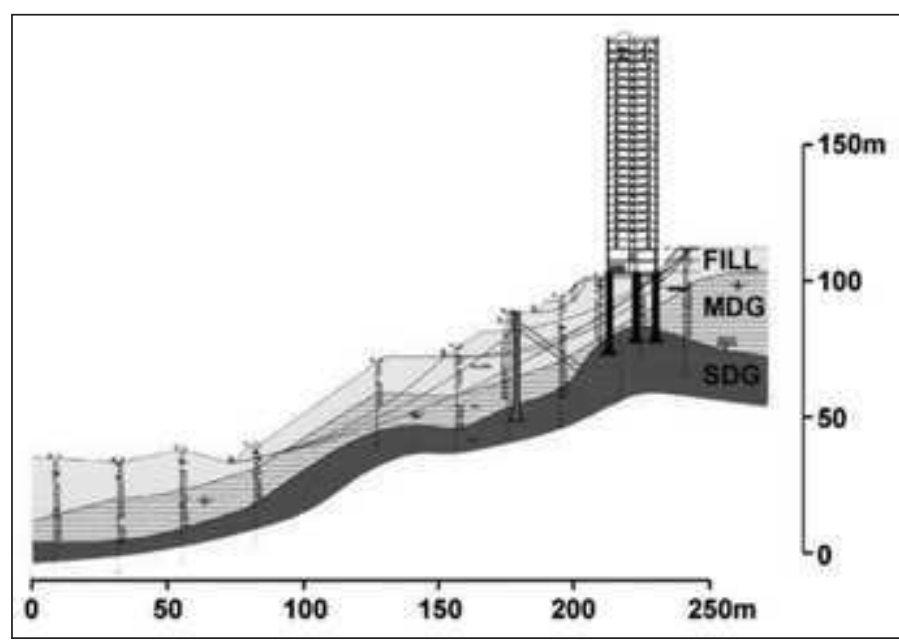

Figure 15: Residential block at the top of a marginally stable slope

The need for two combinations can also be justified on the basis of probability theory, using an approach provided by Eurocode "Basis of Design" (BS EN 1990:2002). The concepts are essentially the same as those of the " $\lambda$-method" discussed in above.

One of the aims of design is to achieve roughly constant reliabilities irrespective of how actions, strengths and resistances combine in particular situations. In Annex C of EN1990, reliability is represented by the target reliability index $\beta$, which represents the number of standard deviations between the characteristic state and the working state. EN1990 defines how the values of partial factors might be selected in order to achieve this, proposing that factors could be applied simultaneously to actions and strengths (or action effects and resistances). In effect it proposes that the action effects for ULS design should be $0.7 \beta$ standard deviations from their characteristic values, and the margin on resistances should be $0.8 \beta$. But it places an important limit on this approach: it is only applicable if the ratio of the standard deviations of the action effect and resistance, $\sigma_{E} / \sigma_{R}$, lies within the range 0.16 to 7.6. The implication of this is that a different approach is to be used if the uncertainty of one of the variables - actions or resistances - is much more important to the design than is the other one. For such a situation, the margin on the more critical variable is required to be $1.0 \beta$, with a lower margin, $0.4 \beta$, on the less critical variable.

The result of this approach is shown in Figure 16, in which the reliability achieved (in terms of number of standard deviations of the design point from the mean) is plotted against the ratio of the standard deviations expressed as $\sigma_{E} /\left(\sigma_{E}+\sigma_{R}\right)$. The result is normalised by dividing by the required reliability, $\beta$ standard deviations, so that the desired value is 1.0. Over 


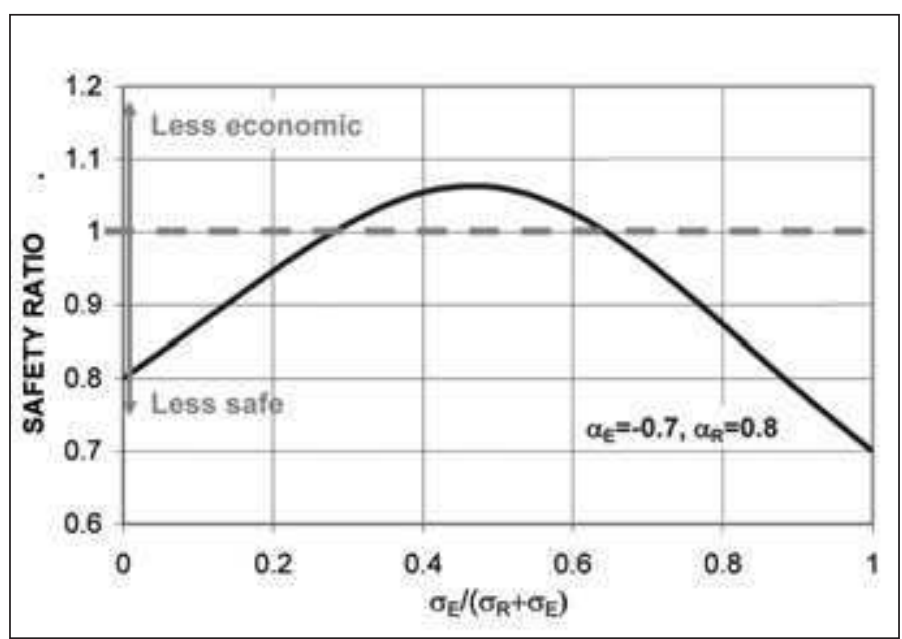

Figure 16: Reliability achieved using $(0.7,0.8)$ combination for $\alpha$

the range in which both $\sigma \mathrm{E}$ and $\sigma \mathrm{R}$ are of similar, significant magnitude, the result is reasonably close to the desired value. However, as either $\sigma_{\mathrm{E}}$ and $\sigma_{\mathrm{R}}$ becomes small compared to the other one, the reliability achieved drops substantially, indicating an unsafe design with inadequate reliability. This explains why EN1990 limits the range of applicability of the approach to $\sigma_{\mathrm{E}} /$ $\sigma_{\mathrm{R}}=0.16$ to 7.6 .

Figure 17 shows that in geotechnical design it is important to consider the full range of $\sigma_{\mathrm{E}} / \sigma_{\mathrm{R}}$ values. Conventional foundations may have $\sigma_{\mathrm{E}}$ and $\sigma_{\mathrm{R}}$ of similar magnitude, but other situations are dominated by either $\sigma_{\mathrm{E}}$ and $\sigma_{\mathrm{R}}$. For example, in slope stability problems there is often very little uncertainty about the loading, so uncertainty of soil strength is dominant, as shown by the fact that factors of safety are normally applied to soil strength. This leads to the need for a different approach to slope stability in DA2. At the other extreme, designs for foundations of tall towers may have loading as the dominant uncertainty. In geotechnical design, these problems often occur together, so the approach adopted must be able to accommodate the full range of $\sigma_{\mathrm{E}} / \sigma_{\mathrm{R}}$.

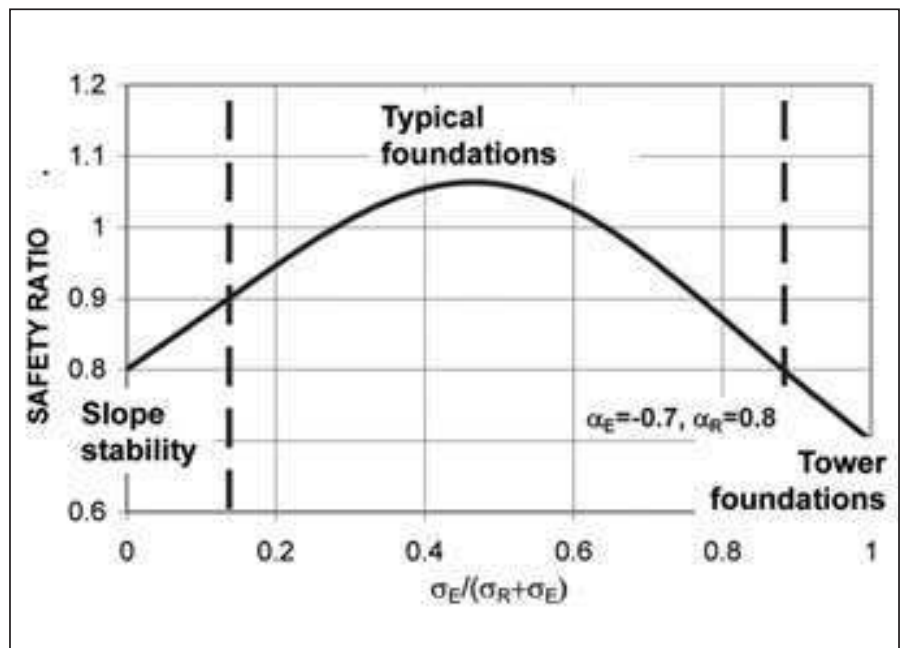

Figure 17: Reliability for some typical geotechnical situations

Figure 18 shows the result in terms of reliability of an approach using two "combinations" in which the margin on the more critical variable is required to be $1.0 \beta$, with $0.4 \beta$ on the less critical variable. Much greater consistency is achieved, with none of the resulting values falling substantially lower than required (ie 1.0).
The benefit of the use of two combinations is that a very wide range of design situations can be covered without change in the design approach. In common with other design approaches, the factors used in DA1 have not been deduced by probabilistic calculation. Nevertheless, they do reflect the principles propounded in EN1990 and the lessons which may be learnt by considering a probabilistic framework.

Although the concept of "combinations" is relatively new to geotechnics, it is familiar to structural engineers who frequently design for several combinations of actions. The background to DA1 is essentially the same as that of combinations of actions, giving a severe value to the lead variable in combination with less severe values of other variables, but in DA1 the method is extended to include resistances or material strengths, as suggested by EN1990. The fundamental principle of DA1 is that "All designs must comply with both combinations in all respects, both geotechnical and structural". The "design" meaning "that which will be built".

\subsection{BRICK - THE FLORENCE CONFERENCE}

In 1991 a European conference of the ISSMGE was held in Florence, Italy. During the conference, Professor Charles $\mathrm{Ng}$ of Hong Kong expressed an interest in using the author's 1979 model for the stress-strain behaviour of stiff clay in further research. This led the author to reflect again on some of the features of soil behaviour already noted earlier:

- Soil behaves as though it has memory, as was demonstrated by the oil storage tanks in Dubai (3.3, above). Sometimes this is made obvious by a change of density, as in the overconsolidation of clays, but this is not always the case: stress re-versals and reloading usually give a stiffer response than initial or monotonic loading. Work from City University (Atkinson et al., 1990) had recently shed light on this.

- Stiffness decays with increasing strain, as had been understood during the design of the British Library excavation (4.1, above). In the Florence conference, Atkinson and Sallfors (1991) discussed the types of testing relevant to the different magnitudes of strain. Their figure was developed by Mair (1993) in the form shown in Figure 19, similar in concept to Figure 11 above.

- Volumetric strain is recoverable to some extent, with stiffness roughly proportional to mean normal effective stress, as in the Cam-clay models. But there is very little recoverable shear behaviour, as also noted in the Cam-clay models but perhaps forgotten in the development of models for use in finite element analysis (2, above).

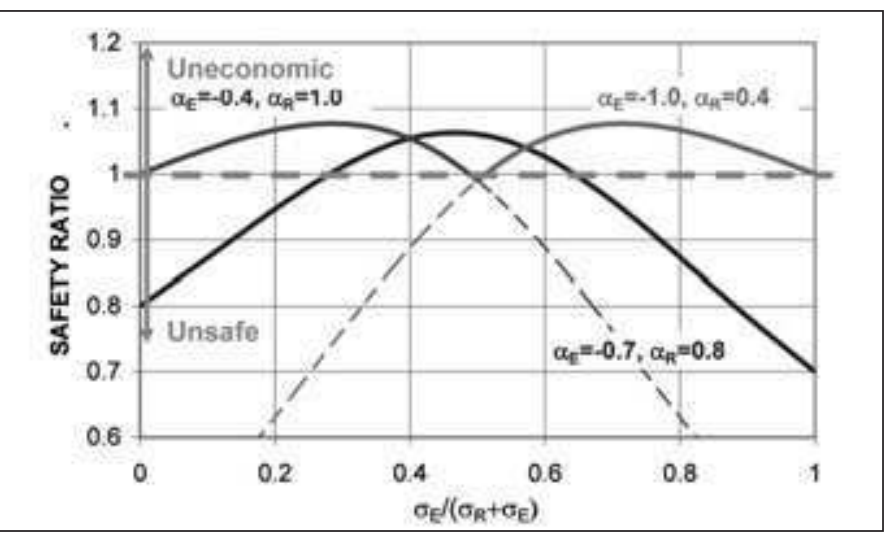

Figure 18: Reliability achieved using $(1.0,0.4)$ combinations for $\alpha$ 


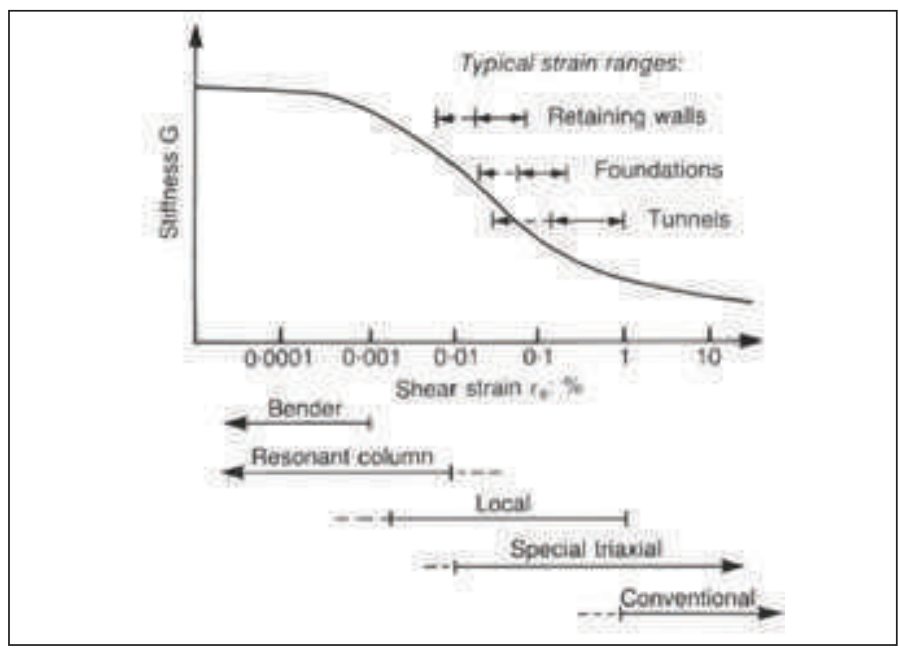

Figure 19: Decay of stiffness with strain. After Mair (1993)

- Strain is important. As Burland had noted: "Stress is a philosophical concept; deformation is the physical reality" (2, above).

The author considered that this behaviour might be best understood by remembering that soil is a particulate material, and that it is the physical movement of particles and their contacts that leads to these stiffness phenomena. As had been proposed in 1979 (4.1, above), it seemed more appropriate to express this movement of particles in strain space than in stress space. Two objects (for example two cars, two paper cups, two sheets of paper), on pristine and one crushed or deformed, may have the same stress states, but their states of deformation or strain hold the "memory" of their different histories.

Florence is a beautiful and inspiring city, and air flights meant that the author had a day to spare after the conference. This gave a great opportunity to think soil mechanics at the same time as absorbing the atmosphere of culture. The result a few days later was a new model of soil behaviour, the BRICK model (Simpson 1992). The value of "time to think", away from the office, was immense.

It was noted that a physical analogue bears a striking resemblance to the features of behaviour listed above. Imagine a man walking around a room and pulling behind him a series of bricks, each on a separate string. Some possible paths for the man and the strings are shown in Fig. 20. If he walks continuously in one direction the bricks line up behind him and follow him (Figure 20(a)). If he turns back (Figure 20(b)) the bricks initially do not move; then the ones on shorter strings start

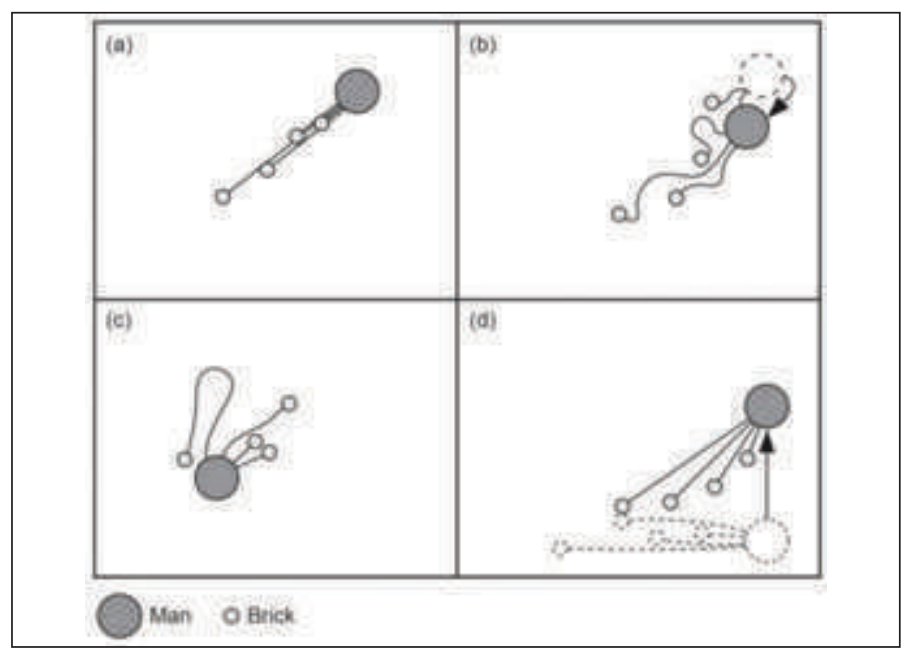

Figure 20: A man pulling bricks attached to him by strings

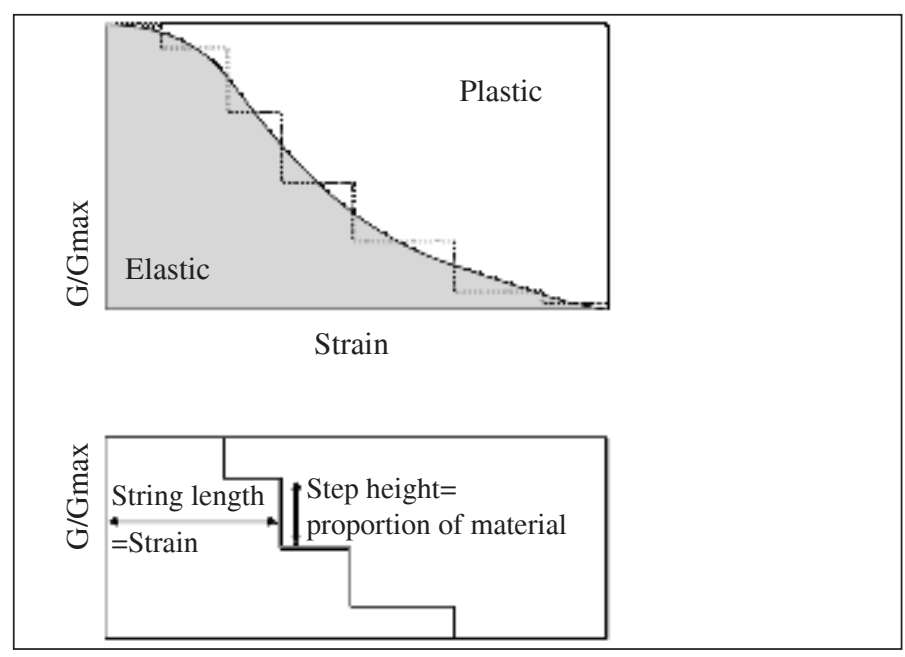

Figure 21: Step wise model of stiffness decay

to move, gradually followed by the longer strings (Figure 20(c)). If he turns through $90^{\circ}$, the bricks initially keep moving in their previous direction but gradually swing round behind him (Figure $20(d))$.

The analogue is found to be remarkably useful if the man is taken to represent the point in strain space of a soil element and each brick represents a proportion the particles in the element. Movement of a brick represents plastic strain, and elastic strain is given by the difference between the movement of the man and the sum of the movements of the bricks, each weighted by the proportion of the soil it represents. In this view, pure elastic behaviour only occurs on the rare occasions when no bricks are moving, i.e. immediately after a reversal of the strain path. It is assumed that only elastic strains cause changes of stress. The S-shaped degradation curve could be modelled in a stepwise fashion as shown in Figure 21. At very small strains, the material is completely elastic; in the analogue, none of the bricks is moving. As straining proceeds one of the bricks starts to move, plastic strain begins and there is a drop in the overall stiffness of the soil. At a larger strain, another brick starts to move; there is more plasticity and a further drop in stiffness, and so on. The length to each step is a strain, represented by the length of a string in the analogue. The height of the step indicates the proportion of material represented by each of the bricks.

Combining this analogue with concepts from the Cam-clay models, and taking parameters only from laboratory testing, Simpson (1992) showed that BRICK could reproduce the observed displacements of the British Library excavation, tending to give displacements on the high side of the measurements. Parameters for London Clay have been refined in later work by Pillai (1996) and others, and have been developed for other clays (eg Jovičić et al., 2006).

\subsection{HEATHROW}

A serious collapse occurred at Heathrow Airport near London in 1994, during construction of an underground railway station for the Heathrow Express (HSE 2000). Figure 22 shows the geometry of the three tunnels that collapsed and gives an indication of the collapse mechanism, caused by construction problems in the NATM linings of the tunnels. From an analytical point of view, the ground deformations that take place at tunnels during construction, remote from collapse, are more difficult to compute. 


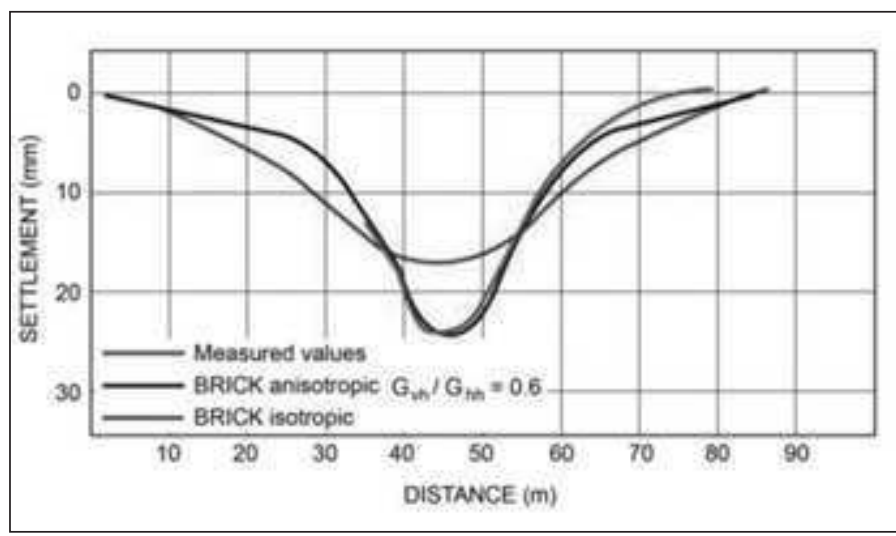

Figure 22: Heathrow station trial tunnel: comparison of isotropic and anisotropic BRICK models with observed surface settlements

\subsection{Brick}

Prediction of the settlement trough observed at the ground surface as a result of tunnel construction has been, and remains, one of the biggest challenges and puzzles for finite element modellers. Almost all stress-strain models fail to predict the narrowness and depth of the troughs that are normally observed. Careful monitored trials of tunnelling techniques were carried out for the construction of the Heathrow Express railway in the UK, and attention became sharply focussed on this following a collapse in 1994. For pre-collapse deformation, it was realised that isotropic linear elastic models were useless. Small strain models such as BRICK are somewhat better, but Figure 22 shows that agreement between computed and observed surface settlements is still not good.

Figure 22 also shows that much better results could be obtained by assuming that the London Clay is significantly anisotropic in its shear behaviour; that is, the stiffness modulus for shearing in the vertical plane, Gvh, is smaller than that for shearing in the horizontal plane, Ghh. This feature that has been confirmed, at least for small strains, by field shear wave and laboratory bender element measurements (Simpson et al., 1996, Simpson 1999). Comparisons between results for different trial tunnels at Heathrow also suggested that geological ageing, leading to a loss of shorter term (smaller strain) memory is important; as in humans, short term memory fades with age! In soils, this may be more related to the size of the events, in terms of strain magnitude, than to the details of timing.

The BRICK model has been used in the design of many projects in London (eg Yazdchi et al., 2005, Yeow et al., 2006, Devriendt et al., 2010). Further work on the concepts has been published more recently by Ellison et al., (2012), and current development, related to ageing, is concentrating on time effects such as creep, based on the work of Sorensen et al., (2007) and Clarke and Hird $(2012,2013)$.

\subsection{Water}

A finite element analysis used in the design development of the Heathrow tunnels was published by Atzl and Mayr (1994). They used a Cam-clay model to represent the London Clay and noted that an adjacent borehole was reported as "dry" during drilling. They therefore assumed that there was no water pressure in the London Clay. In reality, the hydrostatic head at the depth of the tunnel would be 15 to $20 \mathrm{~m}$. It may be interesting to speculate that if this water pressure situation had been understood throughout the design development a more robust design might have been adopted, able to withstand the construction problems that actually caused the collapse.

\subsection{PRESENT AND FUTURE - EUROCODE}

For the last three years, fourteen "evolution groups" have been studying various areas for amendment and development of Eurocode 7. The list is as follows:

- EG 0 Management and oversight

- EG 1 Anchors

- EG 2 Maintenance and simplification

- EG 3 Model solutions

- EG 4 Numerical methods

- EG 5 Reinforced soil

- EG 6 Seismic design

- EG 7 Pile design

- EG 8 Harmonization

- EG 9 Water pressures

- EG 10 Calculation models

- EG 11 Characterization

- EG 12 Tunnelling (not active)

- EG 13 Rock mechanics

- EG 14 Ground improvement

Evolution Groups 4, 8 and 9 relate to the themes of this paper. They will produce final reports early in 2015 .

\subsection{Water}

The provisional conclusions of EG9 were noted above in 5.1, above. Some related papers will also be published in the European conference of ISS-MGE to be held in Edinburgh in 2015, including Simpson and Katsigiannis (2015).

\subsection{Safety}

EG8 has the difficult task of trying to provide a rational framework for safety while accommodating a wide range of traditions in Europe. Present discussions suggest some changes in terminology, with an acknowledgement that DA1 Combination 2 for piles and anchors, not discussed in this paper, is essentially similar in application to DA2. The principle of checking two calculations for other forms of design, as in DA1, is endorsed but alternatives will still also be offered.

\subsection{Characterisation}

The characterisation of natural ground, identifying parameter values for use in calculation, is a challenging topic being addressed by EG11. In present practice, this depends heavily on the subjective knowledge and judgement of the engineers involved in the design of each project. This may be inevitable because the designer has available much more information about the variability of the ground and the reliability of any test results than could possibly be known or prescribed by the code drafter.

It would be convenient in terms of contractual issues, and possibly safer, if more objective approaches could be found, perhaps using probabilistic or statistical approaches. The author is concerned that two particular problems must be avoided, as discussed in Simpson (2011).

a. Analysis of data must not be limited to single sets suitable for statistical manipulation. EC7 requires that characteristic values of soil parameters take account of all available 
data, including field and laboratory measurements and also published papers or other established sources. Often this given sets of information that are all relevant but of varying quality and extent, some of which are derived from the engineer's own background. These are not easily incorporated into statistical analysis, but it would be a highly retrograde step to discount any such information.

b. Statistical analysis tends to "pivot" around mean values or data or "most probable" values of parameters. As noted earlier (4.1 and 5.1, above), it is important that designers consider directly what is the worst that can happen, not relying on either factors or statistic to cover the difference between this and mean values. Although EC7's definition of "characteristic values" of parameters does not demand design for the worst that is credible, it does at least warn the designer to move away from a simple mean value and consider the range of possibilities.

These considerations imply that debate between engineers, as they bring together their invaluable subjective knowledge experience, will remain a feature of geotechnical engineering.

\subsection{Deformation and numerical analysis}

Eurocode 7 has little that is new to say about deformation analysis, which relates mainly to serviceability limit states (SLS). Its importance of SLS is recognised and it is acknowledged that it may be the governing factor in designs in some cases. Because reliable calculation of deformation remains difficult, the code offers alternative approaches in some places, such as reference to existing experience or limiting mobilised strength.

EG4 has concentrated on the use of finite element methods for ULS calculations, particularly (a) verifying the design at ULS entirely by FEM without other additional geotechnical calculations, and (b) using the FEM results directly to provide ULS design bending moments and forces for structural design. In order to achieve this, EG4 proposes an approach similar to DA1, with two separate calculations.

Use of FEM for ULS raises a number of other issues of which a full discussion is presented by Simpson and Junaideen (2013). The following is a very brief summary of the conclusions of that paper.

How should strength factors be applied? Although the "c- $\phi$ reduction" method, reducing soil strength until the structure fails, may be informative in some cases, it is not a code requirement and may sometimes be misleading. An approach more in keeping with the code is to factor the data at input to the computation, and then to show that equilibrium can be achieved without overstressing either the ground or the structure.

Does FEM give the wrong failure mechanism? There is no "right" failure mechanism, because failure is not what is required by the code. The code requires a proof of success, and in many cases it is not necessary or helpful to take the analysis to failure.

How can partial factors be applied when advanced soil models are used? This is an ongoing debate. One approach is simply to switch to Mohr-Coulomb models when verifying the design at ULS.

How should partial factors be applied for undrained behaviour and consolidation? The key issue here is that the factor required by the code for undrained strength cu must be operative in undrained computations, even if an effective stress model is employed.
Should factors be applied to KO and soil stiffness? These should not be changed by factors in ULS computations.

In models of staged construction, at what point should strength factors be applied? This is another topic of debate. Opinions generally favour carrying out the main computations with unfactored parameters, then checking individual critical stages with factored parameters.

The overall conclusion of EG4 is that with proper attention to the issues listed above the FEM can be used for ULS analysis. The author anticipates that this will become a widely adopted approach in the near future.

\subsection{CONCLUDING REMARKS}

Engineering of the natural ground will always be challenging, regardless of advances in analytical methods or statistical theory.

Understanding and predicting the deformation of the ground is critically important to many engineering projects, but the stress-strain behaviour of soil, as a particulate material, is extremely complex and not readily reproduced in computer codes. Some advances in understanding its highly non-linear, anisotropic, time-dependent behaviour that have been important in projects have been discussed.

In order to provide adequate safety against ultimate limit states without unnecessary conservatism, it is important to understand what is achieved by applying factors of safety and when it will be necessary to take other approaches. It is important that codes of practice help designers to think about worst case scenarios, not simply what is most likely to happen, and to incorporate all the relevant information available to them, but not necessarily to the code drafter, into this process.

This becomes even more important when water pressures have a particularly dominant role in designs. Applications of factors of safety in ill-conceived ways may lead to ridiculous or unsafe results, and it is probably better to apply no factors to water pressure, but to ensure that the design water pressures used for ultimate limit state design correspond to very extreme scenarios.

The ground holds many secrets, but the job of the geotechnical engineer to is not to work in a secret code but to communicate transparently the uncertainty of the ground's behaviour and the safety provisions that will lead to successful design.

\section{ACKNOWLEDGEMENTS}

The author wishes to thank the organising Committee of the Professor Chin Fung Kee Memorial Lecture for the invitation to present this lecture and paper. Many fruitful discussions with members of EC7 Evolution Groups and with Arup colleagues in the UK, Malaysia and Singapore are also gratefully acknowledged.

\section{REFERENCES}

[1] Atkinson JH, Richardson D, Stallebrass SE, (1990) Effect of recent stress history on the stiffness of overconsolidated soil. Géotechnique 40, 4, 531-540.

[2] Atkinson, J.H. and Sallfors, G. (1991). Experimental determination of soil properties (stress-strain-time). Proc. 10th Euro. Conf. SMFE, Florence, 3, 915-958. 
[3] Atzl G V and Mayr J K. (1994) FEM-Analysis of Heathrow NATM Trial Tunnel. Numerical methods in Geotec. Eng. Ed. Smith, Balkema, Rotterdam.

[4] BS EN 1990:2002 Eurocode: Basis of design. BSI, London.BS EN 1997-1:2004 Eurocode 7: Geotechnical design, incorporating amendment BS EN 1997-1:2004/A1:2013. BSI, London.

[5] Burland J.B. and Hancock, R.J.R. (1977). Underground car park at the House of Commons: Geotechnical aspects. Struct. Engr., vol. $55,87-100$.

[6] Clarke, S. D., \& Hird, C. C. (2012). Modelling of viscous effects in natural clays. Canadian Geotechnical Journal, 49(2), 129-140.

[7] Clarke, S. D., \& Hird, C. C. (2013). Modelling Viscous Effects during and after Construction in London Clay. Geotechnical Engineering Journal of the SEAGS \& AGSSEA, 44(2), 48-54.

[8] Cochrane, GH, Chetwin, DJL and Hogbin, W (1979) Dubai Dry Dock: design and construction. Proc ICE, Vol 66, pp93-114.

[9] Daniels, RJ and Sharp, BN (1979) Dubai Dry Dock: planning, direction and design considerations. Proc ICE, Vol 66, pp76-92.

[10] Devriendt, M, Doughty, L, Morrison, P and Pillai, A. (2010) Displacement of tunnels from a basement excavation in London. Proceedings of the Institution of Civil Engineers - Geotechnical Engineering 163, June 2010 Issue GE3, Pages 131-145.

[11] Ellison, KC, Soga, K and Simpson, B (2012) A strain space soil model with evolving stiffness anisotropy. Géotechnique, Volume 62, Issue 7, January 2012 pages $627-641$.

[12] Environment Agency (2014) Management of the London Basin Chalk Aquifer - Status Report 2014. Environment Agency.

[13] HSE (2000) The collapse of NATM tunnels at Heathrow Airport. Health and Safety Executive, UK.

[14] Jovičić, V, Coop, MR and Simpson, B (2006) "Interpretation and modelling of deformation characteristics of a stiff North Sea clay". Canadian Geotech. J.

[15] Mair, R J (1993) Developments in geotechnical engineering research: Application to tunnels and deep excavations. Unwin Memorial Lecture 1992 Proc. Inst. Civ. Eng.1993.

[16] Orr, TLL (2005) Model Solutions for Eurocode 7 Workshop Examples. Trinity College, Dublin.

[17] Pillai (Kanapathipillai), A (1996) Review of the BRICK model of soil behaviour. MSc dissertation, Imperial College, London.

[18] Roscoe, KH (1970) The Influence of Strains in Soil Mechanics. Géotechnique, Volume 20, Issue 2, pages 129-170.

[19] Ryalls PJ and Stevens A (1990) A large excavation at the New British Library in Central London. Structural Survey 8(1):9-27.

[20] Schofield, A.N. and Wroth, C.P. (1968). Critical State Soil Mechanics. Mc Graw-Hill.

[21] Simpson, B. and Wroth, C.P. (1972) Finite element computations for a model retaining wall in sand. Proc. 5th Euro. Conf. Soil Mech. and Found. Eng.1, 85 - 93 Madrid. 1972.

[22] Simpson, B. (1973) Finite elements applied to problems of plane strain deformation in soils. $\mathrm{PhD}$ thesis, University of Cambridge.

[23] Simpson, B., O'Riordan, N.J. and Croft, D.D. (1979). A computer model for the analysis of ground movements in London Clay. Géotechnique, 29, No. 2, 149-175.

[24] Simpson, B., Calabresi, G., Sommer, H. \& Wallays, M. (1981a). Design parameters for stiff clays. Proc. 7th Euro. Conf. SMFE, Brighton, 1979, 5, 91-125.
[25] Simpson B, Pappin J W \& Croft D D (1981b) An approach to limit state calculations in Geotechnics. Ground Engineering, September 1981, 21-28.

[26] Simpson B, Lance G A \& Wilkinson W B (1987) Engineering implications of rising groundwater levels beneath London. Proc. 9th Euro. Conf. SMFE, Dublin. Accepted for publication in 1987.

[27] Simpson B, Blower T, Craig R N and Wilkinson W B (1989). The engineering implications of rising groundwater in the deep aquifer beneath London. CIRIA Special Report 69.

[28] Simpson B, Atkinson J H \& V Jovičić (1996) The influence of anisotropy on calculations of ground settlements above tunnels. Proc. Int. Symp. Geotechnical aspects of underground construction in soft ground, City University, London.

[29] Clarke, S. D., \& Hird, C. C. (2013). Modelling viscous effects during and after construction in London Clay. Geotechnical Engineering Journal of the SEAGS \& AGSSEA, 44(2), 48-54.

[30] Simpson B (1999) Engineering needs. Proc. 2nd Int. Symp Prefailure deformation characteristics of geomaterials (IS TORINO 99), pp1011-1026. Balkema.

[31] Simpson B (2007) Approaches to ULS design - The merits of Design Approach 1 in Eurocode 7. ISGSR2007 First International Symposium on Geotechnical Safety \& Risk pp 527-538. Tongji University, Shanghai.

[32] Simpson, B (2011) Reliability in geotechnical design - some fundamentals. Proc 3rd Int Symp on Geotechnical Safety and Risk, pp 501-517, Munich.

[33] Simpson, B, Vogt, N \& van Seters AJ (2011) Geotechnical safety in relation to water pressures. Proc 3rd Int Symp on Geotechnical Safety and Risk, Munich.

[34] Simpson, B, Vogt, N \& van Seters AJ (2011) Geotechnical safety in relation to water pressures. Proc 3rd Int Symp on Geotechnical Safety and Risk, Munich, pp 501-517.

[35] Simpson, B (2012) Eurocode 7 - fundamental issues and some implications for users. Keynote lecture, Proc 16th Nordic Geotechnical Meeting, Vol 1, pp 29-52, Copenhagen. Danish Geotechnical Society.

[36] Simpson, B and Junaideen, SM (2013) Use of numerical analysis with Eurocode 7. Advances in Geotechnical Infrastructure. Edited by C. F. Leung, S. H. Goh \& R. F. Shen. Copyright 2013 Geotechnical Society of Singapore (GeoSS). Published by Research Publishing. ISBN: 978-981-07-49484:doi:10.3850/978-981-07-4948-4 3541

[37] Simpson, B. and Vardanega, P. J. (2014). Results of monitoring at the British Library excavation. Proceedings of the Institution of Civil Engineers - Geotechnical Engineering, Volume 167, Issue 2, April 2014, pp 99-116.

[38] Simpson, B \& Katsigiannis, G (2015) Safety considerations for the HYD limit state. Submitted for ECSMGE, Edinburgh.

[39] Sorensen KK, Baudet, B and Simpson, B (2007) Influence of structure on the time-dependent behaviour of a stiff sedimentary clay. Géotechnique 57, 1, 113-124.

[40] Wroth, CP and Simpson, B. (1972) An induced failure at a trial embankment: Part II finite element computations. Proc. Speciality Conf. Performance of Earth and Earth-Supported Structures, 6779. ASCE, Purdue.

[41] Yazdchi, M.,Yeow, H.C., Young, S. (2005) 3D Finite Element Prediction of Ground Movement Induced by Tunnelling Operation in London Clay. ASCE International Conference on Computing in Civil Engineering, Mexico. 
[42] Yeow, HC, Nicholson, DP and Simpson, B (2006) Comparison and feasibility of three dimensional finite element modelling of deep excavations using non-linear soil models. Proceedings of the International Conference on Numerical Simulation of Construction Processes in Geotechnical Engineering for Urban Environment, 23-24 March 2006, Bochum, Germany. CRC Press.

[43] Zienkiewicz, OC and Naylor, DJ (1971) The adaptation of critical state soil mechanics theory for use in finite elements, Contribution 1, Roscoe Memorial Symposium, Cambridge. Foulis. 